\title{
КОНКУРЕНТНЫЙ БЕНЧМАРКИНГ ПО ДАННЫМ ПУБЛИЧНОЙ ОТЧЕТНОЙ ИНФОРМАЦИИ И ЕГО РОЛЬ В РАЗВИТИИ БИЗНЕСА
}

\author{
(c) 2021 Домбровская Елена Николаевна \\ кандидат экономических наук, доцент департамента аудита и корпоративной отчетности \\ факультета налогов, аудита и бизнес-анализа \\ Финансовый университет при Правительстве РФ, Россия, Москва \\ E-mail: ENDombrovskaya@fa.ru
}

\section{(c) 2021 Ибрагимов Азамат Эдильбекович \\ ассистент аудитора Deloitte \\ E-mail: azamatazna@mail.ru}

В статье рассмотрены особенности конкурентного бенчмаркинга как инструмента развития бизнеса. Практика применения представлена по данным российских строительных компаний. Разработаны направления развития бизнес-стратегий и обоснована приоритетность использования конкурентного бенчмаркинга для повышения эффективности и результативности деятельности компаний.

Ключевые слова: конкурентный бенчмаркинг; развитие бизнеса; отчетная информация; сопоставление; рейтинг; компания-эталон.

Бенчмаркинг относится к инструментам самосовершенствования бизнеса, поскольку связан с поиском и изучением наилучших методов и способов предпринимательства. Они рассматриваются как ориентир для компании и выступают неким эталоном в достижении более высоких показателей эффективности и производительности.

Основное содержание бенчмаркинга заключается в выявлении лучших практик ведения бизнеса у лидеров рынка и внедрении их в компании.

Разработкой и изучением методики и концепции бенчмаркинга за рубежом занимались такие ученые как Б. Андерсен, Р.Кэмп, Г. Уотсон и другие. В России, в свою очередь, с 1996 года отдельные положения и аспекты начали рассматриваться в работах А. К. Казанцева, Д. В. Маслова, Г. Л. Багиева, И. А. Аренкова и др. [1], [8], [9].

По определению Роберта Кэмпа, которого считают отцом-основателем бенчмаркинга, «бенчмаркинг представляет собой поиск и применение на практике лучших методов организации производственных процессов» [6]. Ученые и практики рассматривали несколько различных типов бенчмаркинга, среди которых в большинстве своём выделяются: внутренний, внешний, конкурентный и функциональный.

Внутренний бенчмаркинг основан на проведении анализа собственных филиалов и под- разделений, территориально обособленных от самой организации. Внешний конкурентный бенчмаркинг предполагает сравнение результатов деятельности компании с прямыми конкурентами и на этой основе выявление позиции компании на рынке. Внешний внутриотраслевой бенчмаркинг предполагает сопоставление позиции компании с лидерами по отрасли, а внешний межотраслевой бенчмаркинг базируется на изучении наиболее эффективных процессов деятельности любой организации [3].

В таблице 1 проведено сравнение основных типов бенчмаркинга на основе рассмотрения их типологических характеристик.

В условиях глобализации экономики особого внимания заслуживает конкурентный бенчмаркинг, поскольку он обладает несомненным потенциалом для поиска новых конкурентных преимуществ.

В основу проведенного исследования положена гипотеза о том, что конкурентный бенчмаркинг является инструментом стратегического развития компаний в рыночной среде. Это мнение связано с тем, что в условиях конкуренции разработка стратегии развития невозможна без учета состояния всех игроков на рынке, их возможностей и перспектив [4].

Результаты проведения конкурентного бенчмаркинга зависят от качества и достоверности той информации, на основании которой он 
Таблица 1. Сравнительная характеристика основных типов бенчмаркинга

\begin{tabular}{|c|c|c|c|}
\hline Типы & Объекты изучения и анализа & Преимущества & Недостатки \\
\hline 窟 & $\begin{array}{l}\text { Подразделения и филиалы, } \\
\text { занимающиеся аналогичными } \\
\text { видами деятельности }\end{array}$ & $\begin{array}{l}\text { - доступность сбора инфор- } \\
\text { мации; } \\
\text { - положительные результаты в } \\
\text { развитых компаниях; } \\
\text { - точность в сравнении }\end{array}$ & $\begin{array}{l}\text { - внутренняя замкнутость; } \\
\text { - ограниченность в обзоре; } \\
\text { - необходимость различий в } \\
\text { рабочих процессах различных } \\
\text { подразделений }\end{array}$ \\
\hline 离 & Непосредственные конкуренты & $\begin{array}{l}\text { - ориентация на конкурента } \\
\text { с наилучшими результатами } \\
\text { ведения дел; } \\
\text { - возможность улучшения } \\
\text { своих конкурентных позиций } \\
\text { на рынке }\end{array}$ & $\begin{array}{l}\text { - чрезмерное внимание к } \\
\text { факторам общей конкурен- } \\
\text { тоспособности вместо поиска } \\
\text { передовых методов; } \\
\text { - недоверие конкурентам; } \\
\text { - контроль со стороны анти- } \\
\text { монопольных органов }\end{array}$ \\
\hline 突 & $\begin{array}{l}\text { Аналогичные предприятия, } \\
\text { обслуживающие другие рынки }\end{array}$ & $\begin{array}{l}\text { - доступ к информации; } \\
\text { - соотносимость; } \\
\text { - аналогичность технологий }\end{array}$ & $\begin{array}{l}\text { противоречие с долгосрочной } \\
\text { стратегией роста, установлен- } \\
\text { ной на предприятиях - воз- } \\
\text { можных конкурентах в буду- } \\
\text { щем }\end{array}$ \\
\hline 氞 & $\begin{array}{l}\text { Организации - лидеры по объ- } \\
\text { емам производства, качеству и } \\
\text { продажам }\end{array}$ & $\begin{array}{l}\text { - высокий потенциал нахож- } \\
\text { дения передовых методов; } \\
\text { - стимулирующие результаты; } \\
\text { - доступ к базам данных; }\end{array}$ & $\begin{array}{l}\text { - трудности в адаптации ме- } \\
\text { тодов к другой внутренней или } \\
\text { внешней среде; } \\
\text { - большие затраты времени; } \\
\text { - сложности в сравнении агре- } \\
\text { гированных показателей. }\end{array}$ \\
\hline
\end{tabular}

Источник: составлено авторами на основе [1], [2], [3]

проводится. Давая оценку различным внешним и внутренним источникам информации для проведения конкурентного бенчмаркинга, необходимо отметить, что наиболее информативным, достоверным и качественным источником информации выступает годовая бухгалтерская (финансовая) отчетность, подтвержденная аудиторским заключением. Её основными преимуществами по сравнению с иными источниками информации являются следующие:

1) годовая бухгалтерская (финансовая) отчетность носит публичный характер, то есть доступна любым заинтересованным пользователям, вне зависимости от характера интереса;

2) содержание бухгалтерской (финансовой) отчетности и порядок оценки её статей регламентируется со стороны государства, что повышает уровень доверия к ней и является своего рода гарантией качества представленных в ней данных;

3) обязанность формирования бухгалтерской (финансовой) отчетности для всех субъектов, что позволяет в качестве партнера по бенчмаркингу выбрать совершенно любую компанию как в целом по отрасли, так и вне зависи- мости от нее;

4) унифицированность форм отчётности, что обеспечивает сопоставимость данных, а это является наиболее важным фактором для проведения сравнительного анализа в целом.

Применение инструментария конкурентного бенчмаркинга в практической плоскости проведено для такой сферы, как строительство жилых и нежилых зданий. Это связано с тем, что данный сектор экономики характеризуется высокой конкуренцией, где каждая из существующих и формирующихся фирм имеют единые бизнес-процессы, обусловленные самой технологией производства.

В соответствии с этим даже небольшие компании могут перенимать опыт и лучшие стратегии организаций, осуществляющих свою деятельность в данной отрасли достаточно продолжительный период времени и занимающих лидирующее положение в отрасли в целом.

Такие факторы как высокая капиталоемкость, фондоёмкость производства, стабильный спрос на жилье, высокая конкуренция и другие определяют необходимость разработки стратегии развития компаний, занятых в сфере строи- 
тельства жилых и нежилых зданий.

Одной из крупнейших девелоперских групп компаний полного цикла, специализирующейся на проектах комплексного освоения территорий, является АО «Интеко». Компания ведет строительство жилья в Москве, Ростове-на-Дону, Санкт-Петербурге и Ленинградской области. В портфеле АО «Интеко» - более 80 реализованных проектов суммарной площадью около 4,5 млн. $\mathrm{M}^{2}$.

В настоящее время АО «Интеко» занимает лидирующие позиции на инвестиционностроительном рынке Москвы и по итогам 2020 года находилось на 2 месте в рейтинге застройщиков жилья премиум-класса в целом по стране.

Для оценки финансового состояния и финансовых результатов деятельности компании был проведен анализ основных показателей деятельности по данным публичной бухгалтерской (финансовой) отчетности.

На рисунке 1 приведена динамика показателей платежеспособности АО «Интеко» за 20182020 гг.

Данные рисунка 1 свидетельствуют о том, что в 2020 году на фоне незначительного улучшения показателей платёжеспособности (L1), абсолютной и критической ликвидности (L2 и L3), a также некоторого роста маневренности функционирующего капитала (L5) произошло ухудшение значений показателей, которые определяют перспективные возможности компании в плане финансовой обеспеченности будущего развития. К наиболее тревожным симптомам следует отнести снижение значений коэффициента текущей ликвидности (L4), который характеризует сба- лансированность структуры баланса компании, и утерю собственных оборотных средств к концу 2020 года. На фоне снижения доли оборотных средств в активах (L6) коэффициент обеспеченности собственными оборотными средствами (L7) ушел в зону отрицательных значений, что отражает снижение финансовых возможностей компании и ухудшает финансовую обеспеченность реализации её долгосрочной стратегии.

Динамика среднеотраслевых коэффициентов ликвидности за 2014-2020 г.г., представленная на рисунке 2, свидетельствует о том, что на фоне средних по отрасли показателей АО «Интеко» выглядит совсем неплохо.

Но учитывая отрицательную динамику показателей за трехлетний период, восьмикратное падение выручки компании в 2020 году, а также рост кредиторской задолженности и заемных средств, можно говорить о существенном ухудшении платежеспособности АО «Интеко».

О системном кризисе в деятельности компании свидетельствует и оценка показателей рентабельности, представленная в динамике на рисунке 3. 2020 год принёс АО «Интеко» убытки не только от основной деятельности, но и в целом по всем видам деятельности, что привело к уходу в зону отрицательных значений всех показателей рентабельности - рентабельности продаж (R1), бухгалтерской рентабельности (R2), чистой рентабельности (R3), рентабельности активов (R4) и рентабельности собственного капитала (R5).

Несмотря на то, что 2020 год стал проблемным для большинства предприятий строительной отрасли, оценка среднеотраслевых данных

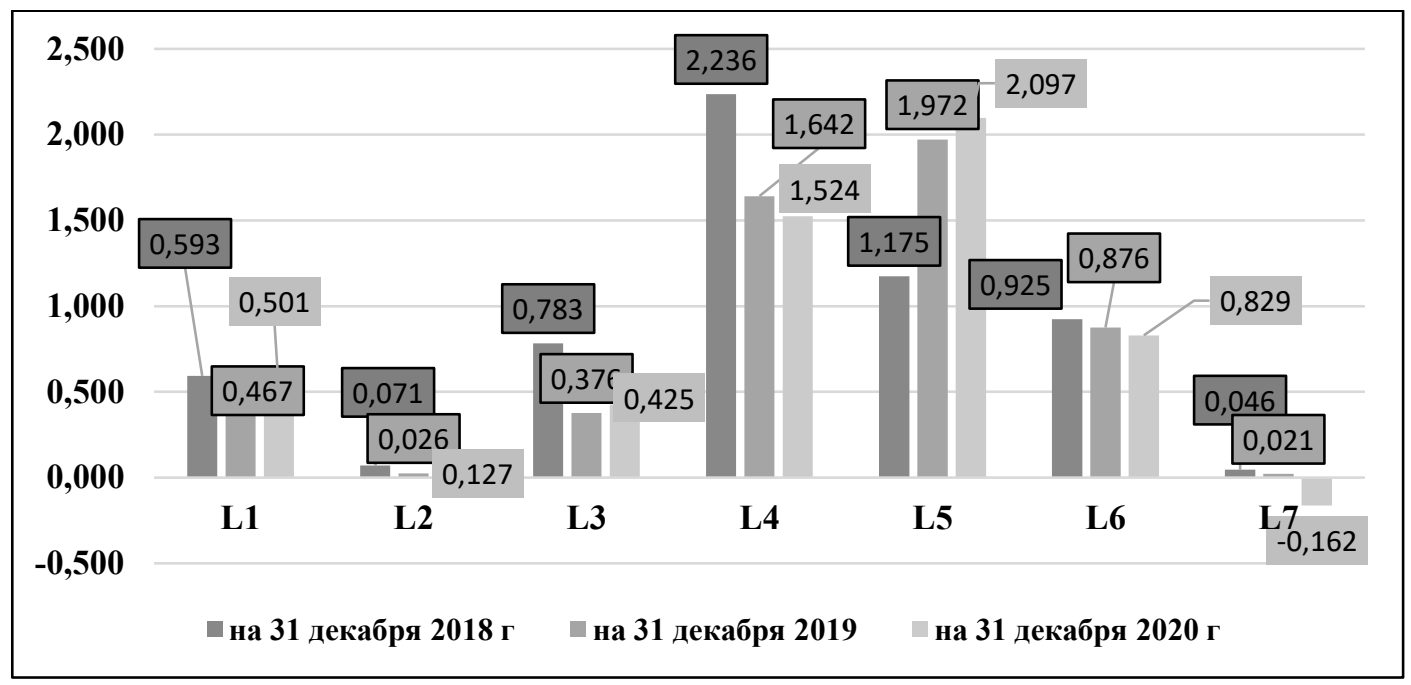

Рисунок 1. Динамика показателей платежеспособности АО «Интеко» за 2018-2020 гг. 


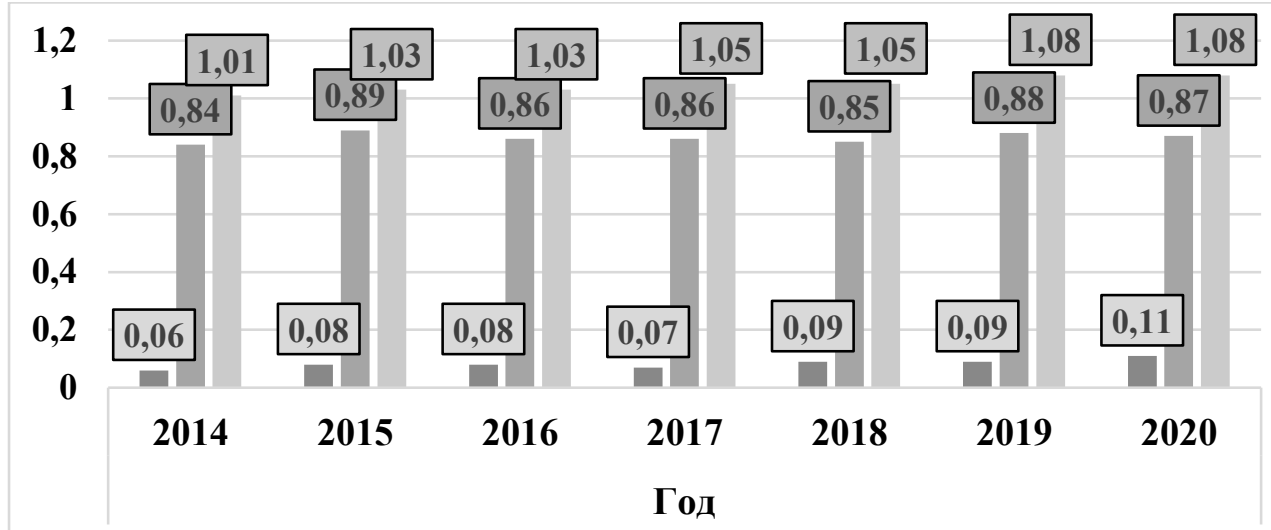

च 1. Коэффициент абсолютной ликвидности (L2)

च 2. Коэффициент «критической оценки» (L3)

3. Коэффициент текущей ликвидности (L4)

Рисунок 2. Динамика среднеотраслевых коэффициентов платежеспособности АО «Интеко» за 2014-2020 гг.

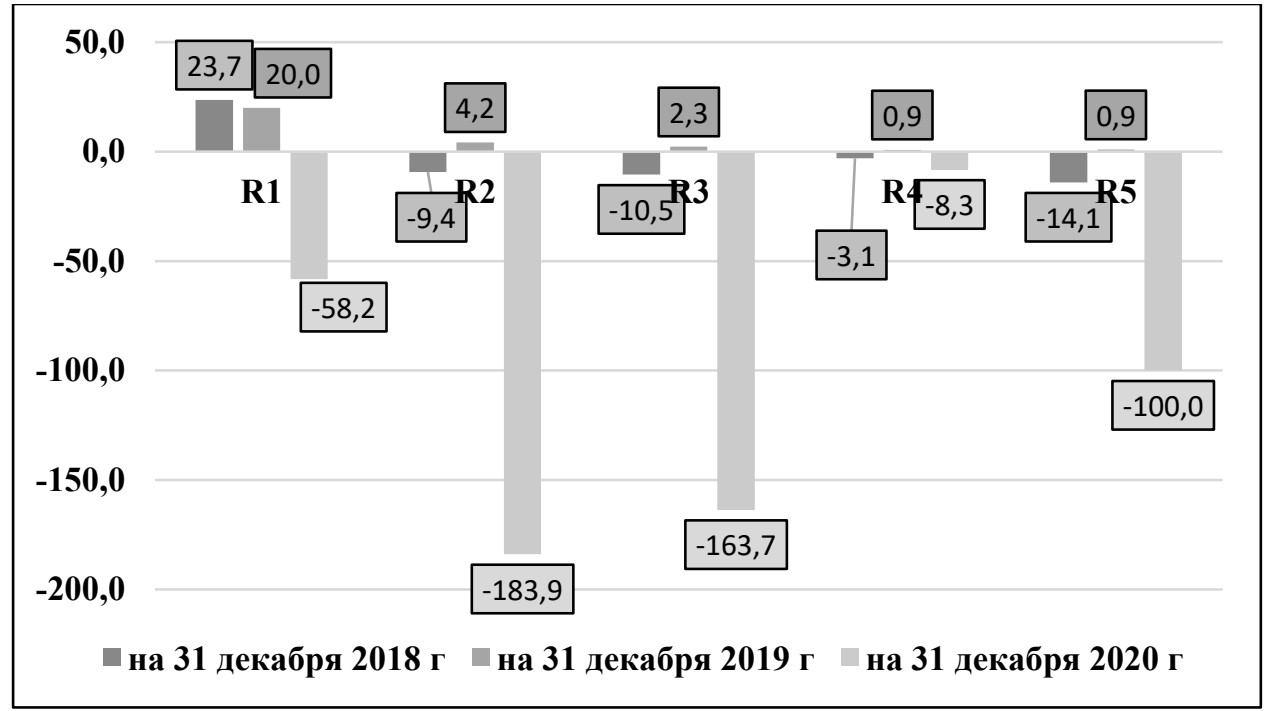

Рисунок 3. Динамика показателей рентабельности АО «Интеко» за 2018-2020 гг.

свидетельствует о том, что отрасль в целом смогла заработать прибыль и обеспечить положительную динамику показателей рентабельности (рисунки 4 и 5).

Существенное ухудшение показателей финансового состояния АО «Интеко» за 20182020 гг. и необходимость формирования антикризисной стратегии выдвигают на первый план поиск инструментов, которые позволили бы компании справиться с возникшими трудностями.

Эффективным и востребованным шагом на пути к повышению эффективности деятельно- сти АО «Интеко» выступает конкурентный бенчмаркинг. Если давать его характеристику с точки зрения субъектов бенчмаркинга и структуры отношений, то данный вид конкурентного бенчмаркинга следует отнести к одностороннему [2].

В основе одностороннего бенчмаркинга нет отношений между компаниями. Эту деятельность ведет только одна компания, в данном случае - $\mathrm{AO}$ «Интеко», чтобы найти лучшие предпринимательские практики в той сфере бизнеса, которая является для компании проблемной.

Односторонний конкурентный бенчмаркинг характеризуется тем, что его инициатор не об- 


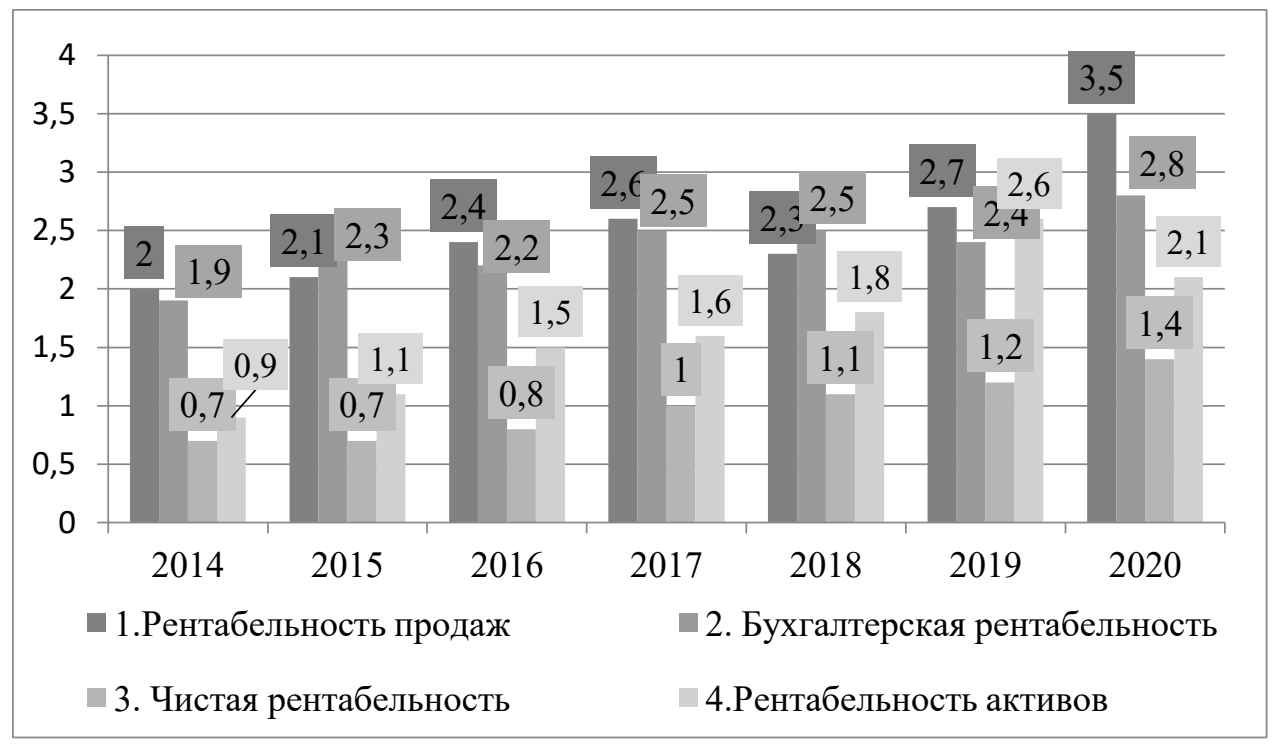

Рисунок 4. Динамика среднеотраслевых рентабельности продаж, бухгалтерской рентабельности, чистой рентабельности и рентабельности активов АО «Интеко» за 2014-2020 гг.

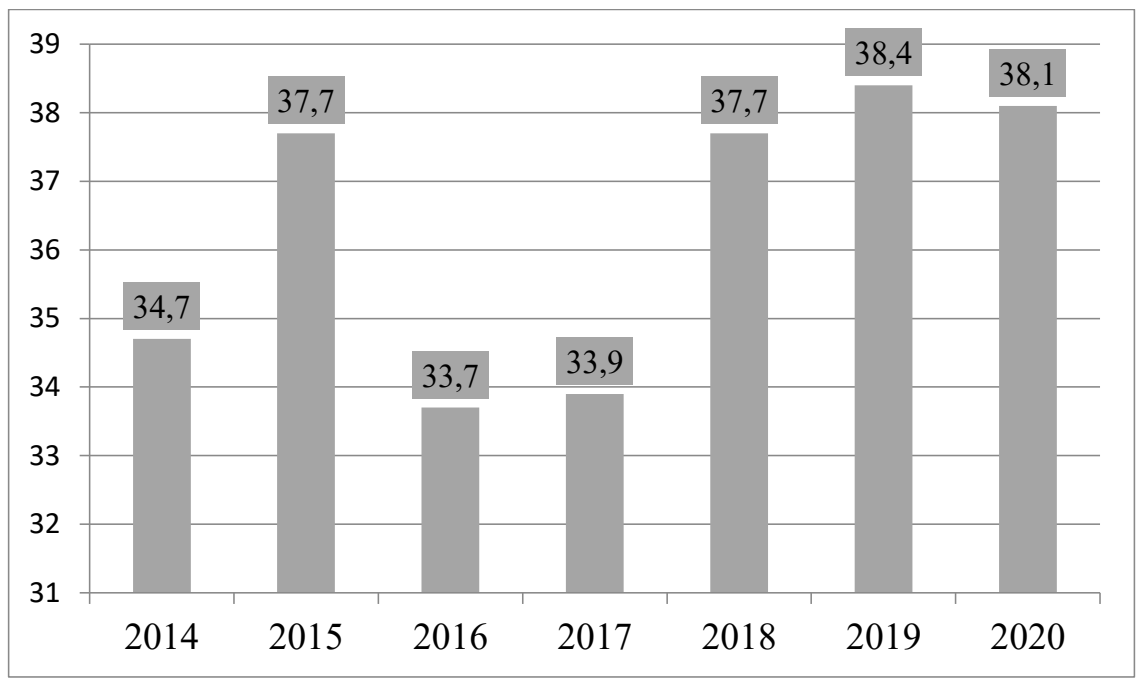

Рисунок 5. Динамика среднеотраслевой рентабельности собственного капитала АО «Интеко» за 2014-2020 гг.

ращается напрямую к компании-конкуренту, а собирает о нем необходимую информацию самостоятельно. То есть, по сути, проводится маркетинговое исследование или конкурентная разведка. Подобную деятельность можно отнести к отраслевому конкурентному анализу. Его информационная база зависит от вида тех проблем, для решения которых компания использует инструменты конкурентного бенчмаркинга. В случае с АО «Интеко» основной выявленной проблемой является ухудшение финансового положения компании и убыточность её деятельности. В связи с этим очевидно, что основным источником информации для проведения конкурентного бенчмаркинга будет вы- ступать бухгалтерская (финансовая) отчетность компании-эталона. Именно она даёт полную картину финансового положения, финансовых результатов и денежных потоков организации, а публичный характер позволяет получить доступ к ней всех заинтересованных пользователей.

В основе проведения конкурентного бенчмаркинга - определенная последовательность действий, шагов, нацеленных на использование опыта более успешной компании-эталона [7].

Первым шагом проведения конкурентного бенчмаркинга стало сравнение основных показателей результативности деятельности и финансового состояния АО «Интеко» со среднеотраслевыми значениями. В итоге проведенного 
сравнения был сделан вывод, что результативность деятельности и финансовое состояние АО «Интеко» хуже средних показателей по отрасли.

Вторым шагом, вытекающим из логики проведения конкурентного бенчмаркинга, является выбор тех показателей, которые положены в основу сравнения с компанией-эталоном [10]. Такими показателями определены коэффициенты ликвидности, платёжеспособности, структуры активов, обеспеченности собственными средствами и показатели рентабельности.

Третьим шагом, этапом конкурентного бенчмаркинга стало определение конкретной компании-конкурента, которая выполнит роль эталона при сравнении установленных показателей. По данным Росстата лидирующее место в отрасли строительства занимает ПАО «ПИК-специализированный застройщик». В 2020 году компания возглавила рейтинг крупнейших застройщиков России [12].

Выбор компании-эталона требует на следующем этапе проведения сравнительного анализа ПАО «ПИК-специализированный застройщик» и $\mathrm{AO}$ «Интеко» по совокупности установленных показателей.

Результаты проведенного сравнения представлены в таблице 2.

Результаты проведённого анализа свидетельствуют о том, что ПАО «ПИК-специализированный застройщик» по состоянию на 31.12.2020 г. достигло лучших значений показателей ликвидности и платёжеспособности, а также обеспечила рентабельность своей дея- тельности, капитала и активов в отличие от АО «Интеко». Хуже по результатам сравнения обстояла ситуация у ПАО «ПИК-специализированный застройщик» с маневренностью функционирующего капитала и обеспеченностью собственными средствами. Тем не менее, рейтинг кредитоспособности ПАО «ПИК-специализированный застройщик», по версии рейтингового агентства «Рейтинг РА», был повышен по состоянию на 15 июня 2021 года до уровня ruA+. Прогноз по рейтингу стабильный. Ранее в отношении ПАО «ПИК-специализированный застройщик» был установлен рейтинг кредитоспособности на уровне ruA.

На следующем, пятом этапе проведения конкурентного бенчмаркинга осуществляется тщательный сбор информации из открытых или любых возможных источников относительно особенностей ведения бизнеса, которые обеспечивают компании «ПИК-специализированный застройщик» лидерство в отрасли и одни из наилучших показателей деятельности.

Анализ характеристических особенностей бизнеса ПАО «ПИК-специализированный застройщик», проведенный на основании открытой информации, показал, что важным фактором, обеспечивающим лидерство компании, стало внедрение проприетарных IT - решений по автоматизации и диджитализации. Благодаря им компания добилась значительного ускорения и оптимизации производственных и бизнес - процессов.

Таблица 2. Сравнительный анализ показателей $\mathrm{AO}$ «Интеко» с компанией-эталоном (ПАО «ПИК-специализированный застройщик») по состоянию на 31.12.2020 г.

\begin{tabular}{|c|c|c|}
\hline Показатели & АО «Интеко» & $\begin{array}{c}\text { ПАО «ПИК-специали- } \\
\text { зированный застрой- } \\
\text { щик» }\end{array}$ \\
\hline 1. Общий коэффициент платежеспособности (L1) & 0,501 & 0,654 \\
\hline 2. Коэффициент абсолютной ликвидности (L2) & 0,127 & 0,322 \\
\hline 3. Коэффициент «критической оценки» (L3) & 0,425 & 1,620 \\
\hline 4. Коэффициент текущей ликвидности (L4) & 1,524 & 2,796 \\
\hline 5. Коэффициент маневренности функционирующего капитала (L5) & 2,097 & 0,655 \\
\hline 6. Доля оборотных средств в активах (L6) & 0,829 & 0,410 \\
\hline $\begin{array}{l}\text { 7. Коэффициент обеспеченности собственными оборотными сред- } \\
\text { ствами (L7) }\end{array}$ & $-0,162$ & $-0,600$ \\
\hline 8. Рентабельность продаж (R1),\% & $-58,2$ & 42,8 \\
\hline 9. Бухгалтерская рентабельность (R2),\% & $-183,9$ & 108,3 \\
\hline 10. Чистая рентабельность (R3),\% & $-163,7$ & 103,1 \\
\hline 11. Рентабельность активов (R4),\% & $-8,3$ & 13,9 \\
\hline 12. Рентабельность собственного капитала (R5),\% & $-100,0$ & 47,6 \\
\hline
\end{tabular}


Факторами конкурентоспособности компании стали географическая диверсификация объектов строительства и диверсификация продуктовой линейки компании. ПАО «ПИК-специализированный застройщик» обеспечивает в больших масштабах строительные работы в регионах: в Краснодарском крае $-5,8 \%$, в СанктПетербурге $-5,2 \%$, в Москве $-4,7 \%$, в Ленинградской области - 3,5\%, в Республике Татарстан $-3,2 \%$, в Ростовской области $-3,1 \%$, в Республике Башкортостан - 3\%, в Свердловской области $-2,8 \%$, в Самарской области $-2,4 \%$, в Новосибирской области $-2,3 \%$, в Воронежской области $-2,2 \%$, в Челябинской области $-2 \%$. В перечисленных субъектах РФ построено около половины от общей площади жилья, введенной в России. В то же время как почти весь объем строительства компании Интеко приходится на Москву и Московскую область [11].

Анализ ценовой политики ПАО «ПИК-специализированный застройщик» свидетельствует о диверсификации продуктовой линейки компании. В сегменте продажи жилья она ориентируется на разных по платежным возможностям покупателей, продавая и простые секционные квартиры, и дорогостоящие апартаменты, и виллы. Прейскурант включает цены начиная с 50 тыс. руб. до 250 тыс. руб. за квадратный метр, что позволяет компании охватывать весь рынок строительства и откликаться на любой запрос клиента, формирующего спрос. В то же время минимальная цена за квадратный метр в Москве у АО «Интеко» приближена к 100 тыс. руб., что почти в 2 раза больше, чем у ПАО «ПИК-специализированный застройщик».

Производственная деятельность ПАО «ПИК-специализированный застройщик» носит инновационный характер. Она связана с непрерывным обновлением номенклатуры продуктовой линейки с учетом применения современных технологий, позволяющих ускорить скорость строительства объектов жилой недвижимости, а также учесть меняющиеся предпочтения покупателей. Удержанию лидирующих позиций компаний и росту эффективности деятельности способствует отмеченное выше внедрение проприетарных IT - решений по автоматизации и диджитализации.

Как фактор конкурентоспособности следует отметить известность и узнаваемость бренда во всех регионах деятельности. Компания запустила новый сервис ПИК Франшиза, который предоставляет готовые решения по управлению бизнесом для девелоперов в России и СНГ.

Также необходимо заметить большой опыт ПИК в разработке и реализации всевозможных маркетинговых программ, максимально учитывающих интересы и желания различных групп населения, заинтересованных в приобретении жилья, таких как гибкие условия по рассрочке, прозрачная система скидок и многие другие. Так, доля сделок с использованием ипотечных кредитов составила $65 \%$ от общего объема реализации жилья [11].

Учитывая всю важность перечисленных направлений деятельности, ПАО «ПИК-специализированный застройщик» совместно с банками-партнерами регулярно проводит для потребителей выгодные акции, в результате которых они имеют возможность получить всю необходимую информацию по жилым комплексам, подбору квартиры, ознакомлению с условиями ипотечного кредитования в любых офисах компании.

В рамках диверсификации ПАО «ПИК-специализированный застройщик» была разработана принципиально новая серия в панельном домостроении, значительно улучшившая потребительские характеристики продукта при сохранении преимуществ индустриального домостроения. Кроме нее разработаны типовые решения для неиндустриального домостроения.

В таблице 3 представлены данные, полученные на основании результатов проведенного сравнительного анализа, демонстрирующие наглядно различия в основных параметрах процессов строительства в компаниях ПАО «ПИК-специализированный застройщик» и АО «Интеко».

На завершающем, шестом этапе проведения конкурентного бенчмаркинга должны быть обобщены полученные аналитические результаты и сформированы предложения по корректировке стратегии развития АО «Интеко» с учетом выявленных конкурентных преимуществ компании-эталона ПАО «ПИК-специализированный застройщик».

По результатам проведенного сравнения очевидно, что финансовые проблемы АО «Интеко» связаны с реализацией производственной, сбытовой, маркетинговой и управленческой стратегиями компании. Выявленными факторами низкой конкурентоспособности АО «Интеко» являются недостаточная диверсифицирован- 
Таблица 3. Различия в основных параметрах процессов строительства в компаниях ПАО «ПИК-специализированный застройщик» и АО «Интеко»

\begin{tabular}{|c|c|c|}
\hline Критерии & $\begin{array}{c}\text { ПАО «ПИК-специализированный за- } \\
\text { стройщик» }\end{array}$ & АО «Интеко» \\
\hline $\begin{array}{l}\text { Диверсификация объектов стро- } \\
\text { ительства и охват локальных } \\
\text { рынков }\end{array}$ & $\begin{array}{l}\text { Осуществление строительства более } \\
\text { чем в десяти крупных регионах Россий- } \\
\text { ской Федерации }\end{array}$ & $\begin{array}{l}\text { Преимущественная концен- } \\
\text { трация всех производствен- } \\
\text { ных мощностей в Москве и } \\
\text { Московской области }\end{array}$ \\
\hline Гибкость ценовой политики & $\begin{array}{l}\text { Цены на жилье за квадратный метр } \\
\text { варьируются в промежутке от } 50 \text { до } 250 \\
\text { тыс. руб. }\end{array}$ & $\begin{array}{l}\text { Минимальная цена на жилье } \\
\text { за квадратный метр около } 100 \\
\text { тыс. руб. }\end{array}$ \\
\hline $\begin{array}{l}\text { Применение новейших технологий } \\
\text { в реализации производственных } \\
\text { бизнес-процессов }\end{array}$ & $\begin{array}{l}\text { Внедрение проприетарных IT-решений } \\
\text { по автоматизации и диджитализации }\end{array}$ & $\begin{array}{l}\text { Реализация производствен- } \\
\text { ных бизнес-процессов с } \\
\text { помощью традиционных } \\
\text { методов }\end{array}$ \\
\hline $\begin{array}{l}\text { Известность и узнаваемость брен- } \\
\text { да }\end{array}$ & $\begin{array}{l}\text { Внедрение нового сервиса ПИК Фран- } \\
\text { шиза, что обеспечивает дополнитель- } \\
\text { ные доходы с минимальными затрата- } \\
\text { ми }\end{array}$ & $\begin{array}{l}\text { Меньшая узнаваемость брен- } \\
\text { да вследствие низкой дивер- } \\
\text { сификации объектов строи- } \\
\text { тельства по географическим } \\
\text { сегментам }\end{array}$ \\
\hline $\begin{array}{l}\text { Реализация различных маркетин- } \\
\text { говых программ }\end{array}$ & $\begin{array}{l}\text { Победитель в номинации «Лучший } \\
\text { партнер по ипотечному кредитованию в } \\
\text { Московском регионе» в рамках сотруд- } \\
\text { ничества с БМ-банком }\end{array}$ & $\begin{array}{l}\text { Данная работа в компании } \\
\text { проводится недостаточно }\end{array}$ \\
\hline
\end{tabular}

ность деятельности, отсутствие гибкости при проведении ценовой политики, недостаточный уровень автоматизации и диджитализации бизнеса и в итоге - невысокая популярность бренда.

В качестве рекомендаций для АО «Интеко» по результатам проведенного конкурентного бенчмаркинга целесообразно выделить следующие направления развития бизнес-стратегий:

1) территориальная диверсификация;

2) расширение рынков сбыта с ориентацией на среднего покупателя;

3) использование новаций в процессе реализации жилых и нежилых помещений для стимулирования спроса;

4) принятие участия в государственных программах поддержки различных групп населения для популяризации бренда;

5) использование современных digitalтехнологий для оптимизации бизнес-процессов и упрощения внутренних и внешних коммуникаций.

Использование конкурентного бенчмаркинга дает очевидные возможности для разви- тия бизнеса и повышения его эффективности. К преимуществам инструментов бенчмаркинга следует отнести логичность и понятность механизма проведения, возможность использования общедоступной публичной информации и наглядность полученных результатов. Конечно, как и у любого инструмента, у бенчмаркинга есть ограничения, которые необходимо учитывать. К ним относится необходимость обоснования при выборе эталонного объекта, а также невозможность слепого копирования чужого опыта без учета собственных возможностей и достижений. Однако, важным преимуществом конкурентного бенчмаркинга является возможность посмотреть на компанию «со стороны», сравнить с лучшими практиками. Это позволяет понять её текущие конкурентные позиции и сгенерировать новые идеи и управленческие решения, уже доказавшие свою эффективность. Именно инновационность результатов конкурентного бенчмаркинга ставит его на первые позиции среди современных инструментов развития бизнеса. 


\section{Библиографический список}

1. Аренков И.А. Бенчмаркинг и маркетинговые решения: монография / Аренков И.А., Багиев Г.Л.- СанктПетербург. 1997. 144 с.

2. Березин А.А., Коваленко А. И. Бенчмаркинг в системе конкурентных действий предпринимательских структур: Современная конкуренция. 2014. № 5(47). С.117-127.

3. Громов А.И. Управление бизнес-процессами: современные методы: монография / А.И.Громов, А. Фляйшман, В.Шмидт; под редакцией А. И.Громова.- Москва: Юрайт, 2019. 367 с.

4. Семеркова Л.Н. Формирование механизма бенчмаркингового взаимодействия предприятий в сфере инновационной деятельности: монография / Семеркова Л. Н., Шерстобитова Т. И. - Москва: НИЦ ИНФРА - М, 2018. 160 c.

5. Виноградова А.И., МарусининаЕ.Ю. Использование бенчмаркинга как эффективного инструмента повышения конкурентных преимуществ компании: Инновационная экономика, перспективы развития и совершенствования. 2017. №4. С. 28-33.

6. Батырова Н.С. Информационно-аналитическое обеспечение стратегии устойчивого развития компании: автореф. дисс. ... канд. экон. наук / Финансовый ун-т при Правительстве РФ. М., 2015.

7. Игнатьев С.В. Инструментарий интенсивного экономического роста на основе бенчмаркинга: зарубежный и российский опыт: МИР (Модернизация. Инновации. Развитие). 2018 Т.9. №1 С.137-147.

8. Казанцев А. К. Концепция бенчмаркинга в современном инновационном менеджменте: Гуманитарные науки. 1997. № 3. С.14.

9. Маслов Д.В., Белокоровин Э.А. Бенчмаркинг - новое слагаемой успешной стратегии бизнеса в России: Деловое совершенство. 2006. № 3

10. Рейтинговая оценка предприятия: [сайт]. - Москва, 2019. - Текст: электронный. - URL: https://all - sci.net/ finansovyiy - analiz_729/reytingovaya - otsenka - predpriyatiya.html

11. Информационно-аналитическая система СПАРК: проверка контрагента: [сайт].- Москва, 2020.- Текст: электронный. - URL: http://www.spark- interfax.ru/promo/

12. Единый ресурс застройщиков: [сайт]. - Москва, 2020.- Текст: электронный. - URL: http:// erzrf.ru/ 